\title{
COMMENT
}

\section{Characteristics of mangrove swamps managed for mosquito control in eastern Florida, USA: a re-examination}

\author{
Jorge R. Rey ${ }^{1, *}$, Sheila M. O'Connell ${ }^{1}$, Douglas B. Carlson ${ }^{2}$, Ronald E. Brockmeyer Jr. ${ }^{3}$ \\ ${ }^{1}$ University of Florida, Florida Medical Entomology Laboratory, 200 9th Street SE, Vero Beach, Florida 32962, USA \\ ${ }^{2}$ Indian River Mosquito Control District, 5655 41st Street, Vero Beach, Florida 32967, USA \\ ${ }^{3}$ St. Johns River Water Management District, PO Box 1429, Palatka, Florida 32178, USA
}

\begin{abstract}
A recent study by Middleton et al. (2008; Mar Ecol Prog Ser 371:117-129) characterizing mangrove swamps impounded for mosquito control in Florida has a number of problems that weaken some of the resulting conclusions. We examine some of these issues, which we divide into (1) errors of fact, (2) methodological problems, (3) unwarranted conclusions. Errors of fact include incorrect historical assertions, incorrect site descriptions, and inaccurate statements on the general effects of impoundments. Methodological problems include inadequate sampling for the stated purpose, in particular using results of one-time sampling of very small marsh areas to characterize entire marshes and groups of marshes; defining inadequate controls; use of heterogeneous experimental treatment groups, including highly atypical and unrepresentative sites within experimental treatments; selective sampling; and others. Unwarranted conclusions include the characterization and comparison of marshes and management strategies based upon unrepresentative sampling, and the attribution of differences in habitat function as a result of management strategy without any experimental evidence to suggest such an effect. We make suggestions for mitigating some of these issues.
\end{abstract}

KEY WORDS: Mangrove $\cdot$ Coastal wetland $\cdot$ Impoundment $\cdot$ Florida $\cdot$ Mosquito

Middleton et al. (2008) attempt to characterize mangrove swamps impounded for mosquito control along the east central coast of Florida with a limited suite of field measurements. Here we point out some issues with the study that we believe complicate the evaluation of their results and raise questions about the conclusions. The major problems fall into 3 categories: (1) errors of fact, (2) methodological problems, and (3) unwarranted conclusions. We use the term 'wetland' instead of 'marsh' or 'swamp', as some of the sites in question are mixes of salt marshes with herbaceous halophyte cover and swamps with mostly mangrove trees.

\section{ERRORS OF FACT}

(1) The assertion that 'the entire impoundment site is cleared of trees at the time of construction' (p. 119) is false. There was vegetation damage in some of the early impoundments because of overflooding, but wetlands impounded for mosquito control were never cleared of vegetation during impoundment construction.

(2) A perimeter dike surrounds the whole impoundment (p. 119). In fact, many impoundments, e.g. S. John Knights (listed as 'South Knights Breach' in Middleton et al. 2008), do not have a dike along the upland edge and thus have an upland watershed. 
(3) Several personal communications are wrongly attributed to one of the authors of this comment (DBC). Included among these are references to development of mainland mangrove spits, surveyor's notes, engineering activities, and references to actual ages of marshes (p. 118-119).

(4) The control wetlands are described as being 'adjacent to the open ocean' and thus subject to direct exchange of nutrients and organic matter with the ocean (p. 127). These wetlands are not adjacent to the open ocean but are within the Indian River Lagoon (IRL) and are highly sheltered from the ocean by the entire barrier island, and some are on the mainland side of the IRL. A few in the southern portion near the Fort Pierce Inlet may experience only very limited ocean water influence, and then only during major hurricanes.

(5) The assertion that impoundments cause 'decreased salinity levels' (p. 117) is incorrect. This only occurs when fresh water is used to flood an impoundment, e.g. by pumping from a freshwater canal or flooding from an artesian well or upland runoff (Brockmeyer et al. 1997). Most impoundments are flooded using lagoon water and have salinities very close to that of the IRL (e.g. Carlson 1983, Rey et al. 1990c).

(6) The islands within the Pelican Island National Wildlife Refuge are not under the jurisdiction of the Indian River Mosquito Control District (p. 118); they are under the jurisdiction of the US Fish and Wildlife Service.

(7) The historical vegetation of pre-impoundment wetlands is incorrectly characterized as 'mangrove swamp' (p. 118). The historical (i.e. pre-impoundment) vegetation in many of these high marshes consisted of succulent herbaceous halophytes (e.g. Batis spp., Sali-
Cornia spp. and Sarcocornia spp.) with interspersed black mangroves (Harrington \& Harrington 1961, Provost 1967, 1973, Montague \& Wiegert 1990).

(8) It is misleading to state that that the levees of impoundments subject to rotational impoundment management (RIM) are responsible for restricting tidal flow (p. 127); these systems are high 'marshes' in a microtidal lagoon (Smith 1987), and have always had limited tidal flow (Provost 1973). Some unimpounded wetlands have natural berms (Odum \& McIvor 1990) that can restrict tidal flooding as much as an impoundment dike, and some RIM impoundments are now more subject to 'tidal' influence than they were prior to impoundment (Provost 1973, Rey et al. 1990b).

(9) Conflicting dates are given for the fieldwork; both March 2006 (p. 120) and April 2006 (p. 119) are listed.

\section{METHODOLOGICAL PROBLEMS}

We have concerns about the methodology used in Middleton et al. (2008). In some cases the individual monitoring techniques utilized are adequate, and our concerns are only with the unrepresentative nature of the sampling.

Sampling. The sampling protocol for Middleton et al. (2008) consisted of one-time sampling of very small portions of each site (Table 1) that were not necessarily equivalent from site to site (see 'Location of study plots'), and not representative of even the individual impoundment or wetland. For example, the soils of over 16000 ha of coastal wetlands were characterized based upon one-time samples covering a combined $6.3 \mathrm{~cm}^{2}$ of wetland surface of each study site, and data for many other variables were collected once in only 2 areas of $1 \mathrm{~m}^{2}$ at each site.

Table 1. Summary of the sampling protocol utilized by Middleton et al. (2008); data are per site

\begin{tabular}{|c|c|c|c|c|c|c|}
\hline Variable & Method & Location & $\begin{array}{l}\text { No. of } \\
\text { replicates }\end{array}$ & $\begin{array}{c}\text { No. of } \\
\text { sample dates }\end{array}$ & Sample size & $\begin{array}{c}\text { Total } \\
\text { sampled }\end{array}$ \\
\hline Soil & Core & Within $1 \mathrm{~m}^{2}$ plot & 2 & 1 & $2 \mathrm{~cm}$ core & $\begin{array}{c}6.3 \mathrm{~cm}^{2} \text { a } \\
15 \mathrm{~cm} \mathrm{deep}^{-}\end{array}$ \\
\hline Ground vegetation & Unknown & Within $1 \mathrm{~m}^{2}$ plot & 2 & 1 & $1 \mathrm{~m}^{2}$ & $2 \mathrm{~m}^{2}$ \\
\hline Crab Holes & Direct count & Within $1 \mathrm{~m}^{2}$ plot & 2 & 1 & $1 \mathrm{~m}^{2}$ & $2 \mathrm{~m}^{2}$ \\
\hline Salinity & Refractometer & Within $1 \mathrm{~m}^{2}$ plot & 2 & 1 & 1 point & 2 points \\
\hline Litter & Visual estimate & Within $1 \mathrm{~m}^{2}$ plot & 2 & 1 & $1 \mathrm{~m}^{2}$ & $2 \mathrm{~m}^{2}$ \\
\hline Canopy openness & Photo & Within $1 \mathrm{~m}^{2}$ plot & 2 & 1 & - & - \\
\hline Propagules & Direct count & Within $1 \mathrm{~m}^{2}$ plot & 2 & 1 & $1 \mathrm{~m}^{2}$ & $2 \mathrm{~m}^{2}$ \\
\hline Mangrove dominance & Visual estimate? & Unknown & $2 ?$ & 1 & Unknown & Unknown \\
\hline Tree height & $\begin{array}{l}\text { Range finder or } \\
\text { stadia rod }\end{array}$ & $\begin{array}{l}\text { Within } 10 \mathrm{~m} \text { of } \\
\text { the sample plot }\end{array}$ & 2 & 1 & 1 tree & 2 trees \\
\hline No. of trees & Count & Touching $50 \mathrm{~m}$ transect & 1 & 1 & $50 \mathrm{~m}$ & $50 \mathrm{~m}$ \\
\hline Schinus terebinthifolius & Count? & $\begin{array}{l}\text { Only where salinity } \\
<2.5 \mathrm{psu}\end{array}$ & Unknown & Unknown & Unknown & Unknown \\
\hline
\end{tabular}


Estuaries, coastal marshes, and mangrove forests exhibit a very high degree of temporal and spatial variability (e.g. Tomlinson 1986, Odum \& McIvor 1990, Virnstein 1990). Such variability has been amply documented for impounded and unimpounded coastal wetlands in Florida (Brockmeyer et al. 1997), including some of the same sites used in the study and for some of the same or related variables including pore water chemistry (e.g. Carlson et al. 1983, Rey et al. 1992, Feller et al. 2003); fishes, macroinvertebrates, and plankton (e.g. Gilmore et al. 1982, Gilmore 1987, Rey et al. 1990c,d, 1991, Vose \& Bell 1994, Taylor et al. 1998, Feller et al. 2003, Stevens et al. 2006); soils (e.g. Parkinson et al. 1993, 2006, Rey \& Kain 1993); vegetation dynamics and production including mangrove growth rates (e.g. Lahmann 1988, Rey et al. 1990a,b, Rey 1994), and many others. Because of pressing management considerations at the time, the goal of some of these studies was to evaluate seasonal and within site variability of specific physical and biological variables; thus they provide abundant relevant data on variability because of their repeated measures design.

These and other studies show that isolated, one-spot, one-time measurements such as some of the field data in Middleton et al. (2008) are inadequate for characterizing these wetlands, which are highly variable in space and time (see below). References to Rapid Assessment methodology (p. 118 and elsewhere) are not applicable to the sampling protocol used in the study.

A good illustration of the unrepresentative nature of the sampling is provided by the salinity ranges reported in Middleton et al. (2008, their Table 3); they list pore water $(15 \mathrm{~cm})$ salinities of $4.5 \pm 0.1,3.8 \pm 0.2$, and $3.4 \pm 0.2 \mathrm{ppt}$ (mean $\pm \mathrm{SE}$ ) for control, breached, and RIM impoundments, respectively. These values are highly atypical for coastal wetlands (impounded or not) along the IRL, where pore and surface water salinity usually ranges from the high teens to the mid 50s, depending upon marsh location, time of year and rainfall; salinities often exceed 75 ppt during dry conditions (e.g. Carlson 1983, Lahmann 1988, Rey et al. 1990c,d, 1992, Brockmeyer et al. 1997, Feller et al. 2003).

Although collection of preliminary data to aid in sampling design is not always feasible due to resource limitations, previous work on like or similar systems can provide starting points for designing sampling schemes with adequate spatial and temporal coverage. The following can be used as guides to delimit strata for impounded and control wetlands (see references above): (1) upland edge, (2) areas near berms and dikes, (3) areas near creeks and ditches, (4) high marsh flats, (5) high marsh barrens.

Important periods in the yearly cycle include: (1) immediately before and after culvert opening in autumn, (2) immediately before and after culvert clos- ing in spring, (3) midway through the closed period in summer, (4) midway through the open period in winter, (5) shortly after the autumn water level rise.

Examination of the actual study sites will most likely dictate addition of sampling stations and times, but these suggestions could be useful during the initial planning stages of a study. Appropriate sample sizes, minimum areas, and replication to cover inter-stratum variability (which can be significant) will depend upon specific sites and sampling methods. Obviously some variables such as tree height, mangrove dominance, and canopy cover do not need frequent repeated sampling (in time) and can be reported from infrequent sampling, provided that enough representative stations and replicates are sampled per site. Other variables, such as salinity, crab burrows, and litter cover, will be subject to significant temporal variability and will require much more frequent sampling. If resources are very limiting, the sampling scheme could be restricted to one or a few marsh areas, but these areas need to be clearly defined and identified, and conclusions applied only to those areas.

Study sites. (1) Several of the control sites near the Environmental Learning Center (ELC) described as 'natural swamps' with 'unmanaged hydrology and vegetation' (p. 119) are actually extensively ditched and far from 'natural'. (2) The ELC wetland, categorized as a mainland spit, is on an island, not on the mainland. (3) Several of the control sites (e.g. Hook Point and the spit at Fish House Cove) are not basin forests as stated (p. 118), but are actually overwash sites (sensu Carlson et al. 1983; J. David, pers. comm.) which have different tidal dynamics than the high marshes where the impoundments are located. Control and experimental sites are thus inherently different regardless of management. (4) The authors erroneously group impoundments with different management schemes under the 'RIM management' category. For example: Impoundment 1 (Bear Point), listed as RIM is actually part of a mitigation bank and is managed by continuous pumping with bottom water release to simulate tidal exchange. Impoundments 3, 19B, 14A and 14B in St. Lucie County are managed similarly (J. David, pers. comm.). (5) The Moorings N site, referred to as 'permanently impounded' (pp. 119120 ) is anomalous and not representative of any other site in the IRL. The vegetation at that site was killed during residential development in the 1970s and the adjacent marina pumps water continuously from the marina into the impoundment to provide circulation in the marina. It is not clear why this site was included in the study. (6) Impoundment 14A, was a spoil disposal site (see 'Exotic invasion', below) which also makes it highly atypical from the other sites regardless of management strategy. (7) The S. John Knights site (listed as 
South Knights Breach) referred to as 'breached' actually has an intact dike with one culvert.

Several steps can be taken to mitigate these problems:

- Use appropriate controls (Points 1 \& 3 above). The appropriate 'natural' controls for impoundments would be unimpounded, unditched high marshes, as impoundments were only constructed on high marshes. These types of sites are not easy to find, but they do exist and can be located with the help of local contacts. Clearly, comparisons of impounded high marshes with unimpounded low marsh or overwash sites are not very useful.

- Make sure that the study site descriptions are accurate (Points 1,2, $3 \& 7$ above).

- Define and select homogeneous experimental classes (Points 4, 5 \& 6 above). For example, do not include continuous pump, bottom water release-managed impoundments in the RIM-managed category. Actually, comparison and evaluation of the above 2 management strategies would be an interesting task for future studies.

- Do not include highly aberrant or atypical sites within other experimental classes as these will bias the results for those classes (Points $5 \& 6$ above). Examples from Middleton et al. (2008) include inclusion of Impoundments 14A and 14B that were originally fresh water systems with a substantial watershed and spoil disposal sites (14A) in the traditional RIM-management category.

Location of study plots. No information is given on the location of the 2 sample quadrats within each wetland on whether the 2 plots at each site were at the same elevation relative to NGVD, nor on whether the plots at different sites were at the same relative elevation. It is highly unlikely that plots at different sites were similar in elevation given the haphazard method of establishing the plots ('...near the point of access to the site, (dock, boardwalk or other access point)', p. 120), the small areas covered by the sampling (Table 1), and the differences between sites. Wetland location will greatly influence any measurement collected there, and ignoring it makes their comparisons tenuous. Determination of the elevation of sampling stations, or at least their relative location within and between study sites, should be a priority during the planning stages of studies in coastal wetlands to assure that inherent between-station differences, such as those between a low marsh and a high marsh, do not confound differences associated with the variables of interest (e.g. management strategy).

Wetland 'age'. Middleton et al. (2008) explained that 'For each study site "age" or the time since the last disturbance was determined as the time since the last freeze, the last hurricane, or the time since creation of the site' (p. 119); they concluded that trees attained the greatest height in approximately 40 to $75 \mathrm{yr}$ (p. 125) and plotted 8 sites ranging in age from 0 to $160 \mathrm{yr}$ (Middleton et al. 2008, their Figs. 5 \& 6). However, the Christmas freeze of 1989 killed the mangroves in the study area, so that the trees included in the study were $<20$ yr old in 2006. Only a few trees in overwash sites on the extreme south part of the study area survived the freeze (J. David, pers. comm.). If by chance any of these survivors were present in the control sites (only control sites were located in overwash sites), the trees were there as a result of cold survival and not because of management practices. The date of impoundment construction is irrelevant, because vegetation was not cleared as part of the construction process. Analyses and conclusions based on 'marsh age' are thus unfounded. On a related point, the polynomial regressions relating tree height and percent canopy openness to 'age' (Middleton et al. 2008, their Fig. 5) have only 8 data points, and it is not clear what happened to the other 12 points.

Exotic invasion. Middleton et al. (2008) concluded that RIM impoundments are more prone to invasion by Brazilian peppers Schinus terebinthifolius and that this is 'facilitated by lower salinity of RIM swamps (p. 126)'. However, this conclusion was reached by selectively sampling Brazilian peppers only in RIM wetlands where the salinity was low $(<2.5$ ppt; p. 123); therefore, their results only apply to impoundments where salinities are $<2.5 \mathrm{ppt}$, which are not common along the lagoon (see 'Sampling'). Also, since no information is given on which sites were included in this selective sampling, it is impossible to determine if this conclusion is heavily biased by data from Impoundments $14 \mathrm{~A}$ and 14B, which were historically freshwater systems dominated by Brazilian peppers and cattails (Typha spp.; J. Rey, D. Carlson, R. Brockmeyer, S. O'Connell pers. obs., J. David pers. comm.). Furthermore, salinity is not the only factor influencing the abundance of Brazilian peppers. This species prefers higher elevations, and elevation differences between locations were not considered in Middleton et al. (2008). For example, Impoundment 14A was a spoil disposal site and contains a large spoil bank on which Brazilian peppers are growing because of the high elevation, and behind which peppers are growing because of the hydrological restriction imposed by the spoil bank.

Mangrove species dominance. In 'Materials and Methods', Middleton et al. (2008) stated that mangrove dominance was estimated 'visually' (p. 120), but no explanation was given as to how this was done. Later, however, it was stated that trees touching the transects were counted. It is not possible to determine or evaluate what was actually done to determine dominance. As before, regardless of the specific methods, results will be highly dependent upon the location of the sam- 
pling, and sufficient stratification, replication, and sample sizes are essential if results are to be extended to the whole wetland. Traditional field based mapping/ monitoring of mangroves can be extremely time and resource consuming because of the difficulty in navigating areas with heavy mangrove cover. Remote sensing methods, coupled with adequate ground truthing, can be a great help in such endeavors (Green et al. 1996, Vaiphasa 2006).

Litter cover. Middleton et al. (2008) estimated litter cover in each of 2 quadrats of $1 \mathrm{~m}^{2}$ using arbitrary categories as follows: no litter, a few leaves, some leaves, many leaves, almost completely covered with leaves, and completely covered (p. 120). Percent cover values were then arbitrarily assigned to each category $(0,1$, $25,50,75$, and $100 \%$, respectively). Later, however, the authors stated that 'litter cover on the ground was almost 2 orders of magnitude lower in control swamps than in RIM and breached RIM swamps...' (p. 124). It is not clear how 6-category qualitative data can serve to compute orders of magnitude. Qualitative data such as these can provide useful insights into existing patterns, and assigning ordered numerical values to the categories may help the reader visualize the data. However, in doing so one must not lose sight of the fact that the data remain qualitative and must be treated as such.

Previous research ignored. Considerable research has been conducted on natural and impounded IRL systems since the pioneering work of Provost (e.g. $1959,1967)$ and Harrington \& Harrington $(1961,1982)$. A literature review is beyond the scope of this comment, but the citations given above provide an adequate entry into the literature. This body of research provides abundant comparative data that are directly relevant to the study, but Middleton et al. (2008) only cite a theoretical paper by Montague et al. (1987, cited as 1989) and an impoundment inventory by Rey \& Kain (1990), the latter only to indicate the extent of impounding in the area. Middleton et al. (2008) would have benefited from a more inclusive literature survey.

\section{UNWARRANTED CONCLUSIONS}

Middleton et al. (2008) repeatedly mentioned that descriptive field measurements such as theirs do not reflect complex ecosystem processes, and cited numerous references expressing this. However, they later concluded that their results '...may mirror shifts in ecosystem processes...' (p. 127) and speculated that their findings may indicate changes in ecosystem functions such as nutrient cycling and trophic dynamics (p. 125-126), production, decomposition, and others. These speculations are unsupported; their data simply do not address marsh function nor suggest any such connection. For example, referring to differences in tree heights based on the 2 trees measured per marsh, Middleton et al. (2008) stated that they '...cannot provide any examples on how these specific structural differences in tree height may affect wildlife...' (p. 125), but nevertheless concluded that 'it is possible that height differences in managed mangrove systems may also affect their value as wildlife habitats' (p. 125). They justified their conclusion on the grounds that bald eagles prefer taller older trees for nesting, and that in California, taller forms of the herbaceous Spartina foliosa plants are better for California clapper rails Rallus longirostri obsoletus than shorter $S$. foliosa, facts that are not relevant to mangrove trees in Florida.

Research on coastal wetlands, both managed and unmanaged, is needed, but in the case of Middleton et al. (2008), we think that the validity of the results is questionable and the conclusions are unsupported by the data.

\section{LITERATURE CITED}

Brockmeyer RE, Rey JR, Virnstein RW, Gilmore RG, Earnest L (1997) Rehabilitation of impounded estuarine wetlands by hydrologic reconnection to the Indian River Lagoon, Florida. Wetlands Ecol Manage 4:93-109

Carlson DB (1983) The use of salt marsh mosquito control impoundments as wastewater retention areas. Mosq News $43: 1-6$

Carlson PR, Yabro LA, Zimmerman C, Montgomery JR (1983) Pore water chemistry of an overwash mangrove island. Fla Sci 46:239-249

Feller IC, Whigham DF, McKee KL, Lovelock CE (2003) Nitrogen limitation of growth and nutrient dynamics in a disturbed mangrove forest, Indian River Lagoon, Florida. Oecologia 134:405-415

Gilmore RG (1987) Fish, macrocrustacean and avian population dynamics and cohabitation in tidally influenced impounded subtropical wetlands. In: Whitman WR, Meredith WH (eds) Proc Symp Waterfowl and Wetlands Management in the Coastal Zone of the Atlantic Flyway. Delaware Dept Nat Res and Environmental Control, Dover, Delaware, p 373-394

Gilmore RG, Cooke DW, Donohoe CJ (1982) A comparison of the fish populations and habitat in open and closed salt marsh impoundments in east central Florida USA. Northeast Gulf Sci 5:25-37

Green EP, Mumby PJ, Edwards AJ, Clark CO (1996) a review of remote sensing for the assessment and management of tropical coastal resources. Int J Mar Environ 24:1-40

Harrington RW, Harrington ES (1961) Food selection among fishes invading a high subtropical salt marsh: from onset of flooding through the progress of a mosquito brood. Ecology 42:646-666

Harrington RW, Harrington ES (1982) Effects on fishes and their forage organisms of impounding a Florida salt marsh to prevent breeding by salt marsh mosquitoes. Bull Mar Sci 32:523-531

Lahmann EJ (1988) Effects of different hydrological regimes on the productivity of Rhizophora mangle L.: a case study of mosquito control impoundments at Hutchinson Island, Saint Lucie County, Florida. PhD thesis, University of Miami, 
Coral Gables, FL

Middleton B, Devlin D, Profitt E, McKee K, Getini KF (2008) Characteristics of mangrove swamps managed for mosquito control in eastern Florida, USA. Mar Ecol Prog Ser 371:117-129

Montague CL, Wiegert RG (1990) Salt marshes. In: Myers RL, Ewel JJ (eds) Ecosystems of Florida. University of Central Florida Press, Orlando, p 481-516

Montague CL, Zale AV, Percival HF (1987) Ecological effects of coastal marsh impoundments: a review. Environ Manage 11:743-756

Odum WE, McIvor CC (1990) Mangroves. In: Myers RL, Ewel JJ (eds) Ecosystems of Florida. University of Central Florida Press, Orlando, p 517-548

Parkinson RW, Wang TC, White JR, David JR, Hoffman ME (1993) Distribution and migration of pesticide residues in mosquito control impoundments, St. Lucie County, Florida. Environ Geol 22:26-32

Parkinson RW, Delaune RR, Hutcherson CT, Stewart J (2006) Tuning surface water management and wetland restoration programs with historic sediment accumulation rates: Merritt Island National Wildlife Refuge, east-central Florida, U.S.A. J Coast Res 22:1268-1277

Provost MW (1959) Impounding salt marshes for mosquito control and its effect on bird life. Fla Nat 32:163-170

Provost MW (1967) Managing impounded salt marshes for mosquito control and estuarine resource conservation. In: Newsom JT (ed.) Proc LSU Marsh Estuar Manage Symp 1967. Louisiana State University Press, Baton Rouge, p 163-171

Provost MW (1973) Mean high water mark and use of tidelands in Florida. Fla Sci 36:50-65

Rey JR (1994) Effects of neighbors on growth and mortality of mangrove seedlings in Florida, U.S.A. Wetlands 14: 308-315

Rey JR, Kain T (1990) A guide to the salt marsh impoundments of Florida. University of Florida, Florida Medical Entomology Laboratory, Vero Beach, FL

Rey JR, Kain T (1993) Chemical characteristics of soils in natural and impounded wetlands along the Indian River Lagoon, Florida. U.S.A. Bull Fla Mosq Control Assoc 64: 53-62

Editorial responsibility: Matthias Seaman, Oldendorf/Luhe, Germany
Rey JR, Crossman RA, Kain TR (1990a) Vegetation dynamics in impounded marshes along the Indian River Lagoon, Florida, USA. Environ Manage 14:397-409

Rey JR, Shaffer J, Crossman RA, Tremain D (1990b) Aboveground primary production in impounded, ditched, and natural marshes along the Indian River Lagoon. Wetlands 10:1-21

Rey JR, Shaffer J, Tremain, Crossman RA, Kain T (1990c) Effects of re-establishing tidal connections in 2 impounded tropical marshes on fishes and physical conditions. Wetlands 10:27-47

Rey JR, Peterson MS, Kain TR, Vose FE, Crossman RA (1990d) Fish populations and physical conditions in ditched and impounded marshes in east-central Florida. Northeast Gulf Sci 11:163-170

Rey JR, Kain T, Crossman R, Peterson M, Shaffer J, Vose F (1991) Zooplankton of impounded marshes and shallow areas of a subtropical lagoon. Fla Sci 54:191-203

Rey JR, Shaffer J, Kain T, Stahl R, Crossman R (1992) Sulfide variation in the pore and surface waters of artificial salt marsh ditches and a natural tidal creek. Estuaries 15: $257-269$

Smith NP (1987) An introduction to the tides of Florida's Indian River Lagoon. I: Water levels. Fla Sci 50:49-61

Stevens PW, Montague CL, Sulak KJ (2006) The fate of fish production in a seasonally flooded saltmarsh. Mar Ecol Prog Ser 327:267-277

Taylor DS, Poulakis GR, Kupschus SR, Faunce CH (1998) Estuarine reconnection of an impounded mangrove salt marsh in the Indian River Lagoon, Florida: short term changes in fish fauna. Mangroves Salt Marshes 2:29-36

Tomlinson PB (1986) The botany of mangroves. Cambridge University Press, Cambridge

Vaiphasa C (2006) Remote sensing techniques for mangrove mapping. $\mathrm{PhD}$ thesis, Wageningen University, Enschede, The Netherlands

Virnstein RW (1990) The large spatial and temporal biological variability of the Indian River Lagoon. Fla Sci 53: $249-256$

Vose FE, Bell SS (1994) Resident fishes and macrobenthos in mangrove rimmed habitats: evaluation of habitat restoration by hydrologic modification. Estuaries 17:585-596

Submitted: May 7, 2009; Accepted: August 4, 2009

Proofs received from author(s): August 14, 2009 